\title{
Características de crescimento inicial de duas cultivares de cafeeiro sob diferentes regimes hídricos e níveis de fertilização NPK
}

\section{Initial growth characteristics of two coffee cultivars under different water regimes and levels of NPK fertilization}

\author{
Renan Soares de Souza ${ }^{1 *}$; Celso Helbel Júnior²; Roberto Rezende ${ }^{3}$; André Ribeiro \\ da Costa ${ }^{4}$; Paulo Sérgio Lourenço de Freitas ${ }^{3}$; Rafael Verri Tavore ${ }^{5}$; André Maller ${ }^{1}$
}

\section{Resumo}

O experimento objetivou avaliar os efeitos de regimes hídricos (irrigado e não-irrigado) e fertirrigação, combinados com doses de adubo para N, P e K, na fase de crescimento inicial de duas cultivares de cafeeiro, Obatã e IAPAR-59, na região noroeste do Paraná. O delineamento experimental foi o inteiramente casualizado com parcelas subdivididas. As parcelas foram representadas pelas doses de fertilizantes, correspondentes a $15,30,45$ e $60 \mathrm{~g} \mathrm{~m}^{-1}$, para $\mathrm{N}$ e $\mathrm{K}$, e a 3, 6, 9 e $12 \mathrm{~g} \mathrm{~m}^{-1}$, para $\mathrm{P}$, que equivalem, respectivamente, aos porcentuais de $50 \%, 100 \%, 150 \%$ e $200 \%$ da dose recomendada para cada nutriente. As subparcelas foram constituídas por linhas de plantas que receberam os regimes hídricos. Foram avaliados diâmetro de caule, comprimento do primeiro ramo plagiotrópico e seu número de internódios. Os tratamentos foram analisados separadamente para cada cultivar de cafeeiro. A fertirrigação e a irrigação favoreceram o crescimento inicial de ambas cultivares de cafeeiro. Para a cultivar IAPAR-59, o número de internódios foi superior somente com a fertirrigação. O número de internódios aumentou com a irrigação e diminuiu no sequeiro, de modo linear, para IAPAR-59 e Obatã, respectivamente, em função do aumento das doses de NPK. Na fertirrigação, observou-se redução do diâmetro de caule em doses superiores à menor dose testada, para IAPAR-59, enquanto que o maior número de internódios foi obtido com a máxima dose utilizada, para Obatã.

Palavras-chave: Coffea arabica, irrigação localizada, quimigação, fase de formação

\begin{abstract}
The experiment objectified to evaluate the effects of water regimes (irrigation and no irrigation) and fertigation, combined with fertilizer doses for $\mathrm{N}, \mathrm{P}$ and $\mathrm{K}$, during the initial growth phase of two coffee cultivars, Obatã and IAPAR-59, in the north-western region of the state of Paraná, Brazil. The experimental design was the completely randomized in a split-plot arrangement. The main plots were represented by fertilizer doses, corresponding to $15,30,45$ and $60 \mathrm{~g} \mathrm{~m}^{-1}$, for $\mathrm{N}$ and $\mathrm{K}$, and to $3,6,9$ and $12 \mathrm{~g} \mathrm{~m}^{-1}$, for $\mathrm{P}$, which are equivalent, respectively, to percentages of $50 \%, 100 \%, 150 \%$ and $200 \%$ of the dose recommended for each nutrient. The sub-plots were constituted by lines of plants that received the water regimes. Were evaluated stalk diameter, length of the first plagiotropic branch and its number of inter-knots. The treatments were analyzed separately for each cultivar of coffee. Fertigation and irrigation favored the initial growth of both coffee cultivars. For the IAPAR-59 cultivar, the number
\end{abstract}

\footnotetext{
${ }^{1}$ Discentes de Doutorado em Agronomia, Universidade Estadual de Maringá, UEM, Maringá, PR. E-mail: nansoares86@hotmail. com; anmaller@hotmail.com

${ }^{2}$ Pesquisador Dr. do Instituto Agronômico do Paraná, IAPAR, Londrina, PR. E-mail: celso@iapar.br

${ }^{3}$ Profs. Drs. da UEM, Maringá, PR. E-mail: rrezende@uem.br; pslfreitas@uem.br

${ }^{4}$ Prof. Dr. do Centro Universitário Cesumar, Unicesumar, Maringá, PR. E-mail: rcosta4@hotmail.com

${ }^{5}$ M.e em Agronomia, UEM, Maringá, PR. E-mail: tverri_rafael@hotmail.com

* Autor para correspondência
} 
of inter-knots was upper only with fertigation. The number of inter-knots increased with irrigation and decreased in no irrigation regime, linearly, for IAPAR-59 and Obatã, respectively, in function of the NPK doses increasing. In fertigation, it was observed reduction of stalk diameter at doses higher than the lowest dose tested, for IAPAR-59, while the largest number of inter-knots was obtained with the highest dose used, for Obatã.

Key words: Coffea arabica, localized irrigation, chemigation, formation phase

\section{Introdução}

Para o cafeicultor, a irrigação é uma prática que, além de incrementar a produtividade, pode proporcionar a obtenção de um produto diferenciado e de melhor qualidade, com perspectiva de bons preços no mercado. A fase inicial de crescimento do cafeeiro no campo constitui um período crítico, pois a baixa umidade do solo pode retardar o crescimento das plantas, além da ocorrência de falhas na lavoura, o que pode comprometer o sucesso da cafeicultura (MARTINS et al., 2006).

A região Centro-sul do país é climaticamente apta à cafeicultura, com poucas sub-regiões que apresentam limitações, seja por questões de temperatura mínima ou por deficiência hídrica. Contudo, nota-se que a prática da irrigação tem sido cada vez mais utilizada, principalmente pelos efeitos de estiagens prolongadas nos períodos críticos de demanda de água pelo cafeeiro, o que causa redução de produtividade em várias lavouras (ARANTES; FARIA; REZENDE, 2009).

Notadamente, dois estádios reprodutivos do café podem ser prejudicados com a ocorrência de estiagens: a floração e a granação dos frutos (DAMATTA et al., 2007). No primeiro, a ocorrência de estiagem após a florada faz com que haja menor pegamento dos frutos. Já na granação, a ocorrência de estiagem faz com que aumente a presença de frutos chochos e mal granados. Além desses dois estádios, o crescimento vegetativo do cafeeiro também pode ser prejudicado pela estiagem (PEZZOPANE et al., 2010).

Períodos de seca prolongada reduzem o teor de nutrientes na parte aérea das plantas, podendo causar sintomas de murcha, desfolha, secamento de ramos, morte de raízes e deficiências induzidas de nutrientes. A deficiência, seja ela hídrica ou nutricional, reduz o número de gemas vegetativas e o crescimento de ramos plagiotrópicos, provocando decréscimo na produtividade (JORDÃO; OLIVEIRA JÚNIOR; MENDONÇA, 1996).

Silva et al. (2003), em experimento em Lavras, MG, safra 2001/2002, estudando três épocas de irrigação (01/06 a 30/09, 15/07 a 30/09 e 01/09 a 30/09) e regimes hídricos, observaram que a irrigação realizada entre 01/06 a 30/09 proporcionou maior produção, 58 sacas ha-1, correspondendo à produtividade $186 \%$ superior ao regime de sequeiro. Em experimento com o cafeeiro Topázio MG-1190, também em Lavras, MG, a lâmina de irrigação de 120\% da ECA (Evaporação em Tanque "Classe A") apresentou o maior ganho de altura, diâmetro de copa e comprimento de ramos plagiotrópicos, em relação à testemunha (KARASAWA, 2001).

Testando diferentes lâminas de irrigação, em cafeeiro fertirrigado da cultivar Acaiá Cerrado (MG1474), Alves et al. (2000) observaram aumento linear no diâmetro de caule e comprimento do primeiro ramo plagiotrópico em função do aumento das lâminas de irrigação, sendo o maior valor encontrado para àquela com $100 \%$ de reposição da ECA e o menor valor no regime não-irrigado. Embora este efeito não tenha sido significativo para número de internódios do primeiro ramo plagiotrópico, constatou-se discreta elevação nos valores de $0 \%$ da ECA até $100 \%$ da ECA.

Santana, Oliveira e Quadros (2004), estudando irrigação em diferentes tensões de água no solo, para as cultivares de cafeeiro Obatã e IAPAR-59, constataram que para diâmetro de caule, há diferença entre o uso ou não da irrigação, com os 
tratamentos irrigados impondo maiores valores e de maneira geral, maior taxa de crescimento à planta.

Dentre os vários métodos de irrigação, o localizado é o que tem maior potencial para economia de água e de energia elétrica. Dentro dessa categoria, o gotejamento vem se destacando como um dos principais métodos de irrigação por ter potencial de aumentar a produção e, simultaneamente, conservar o solo, os recursos hídricos e o ambiente. Esse método apresenta ainda outra grande vantagem que é a possibilidade de se efetuar fertirrigações, ou seja, aplicação de fertilizantes via irrigação. A fertirrigação permite melhora na eficiência de uso da água e nutrientes pela colocação simultânea de soluções de nutrientes diretamente na zona radicular, na forma e na quantidade requeridas. Destaca-se também a possibilidade de maior número de parcelamento dos nutrientes sem a necessidade do uso de maquinário e mão-de-obra, além de possibilitar a aplicação independentemente das condições climáticas (COELHO et al., 2009).

A cultivar IAPAR-59, quando comparada com as cultivares comerciais utilizadas no Paraná e na maioria das regiões cafeeiras do Brasil, apresenta menor altura, volume e diâmetro de copa. Além disso, nos primeiros seis anos após a instalação da lavoura, tem boa média de produção anual por planta. A maturação é medianamente precoce e os frutos são vermelhos. Preferencialmente é indicada para regiões mais frias e chuvosas, solos mais férteis e plantios adensados (MATIELLO et al., 2005). A cultivar Obatã é vigorosa e apresenta porte baixo, folhas largas, internódios curtos, boa ramificação secundária e frutos vermelhos de maturação média a tardia. É exigente em nutrição, sensível à seca e indicada para plantios adensados ou em renque (CARVALHO et al., 2008).

Prado e Nascimento (2003) ressaltaram que, em se tratando de adubação de formação, existem na literatura poucos trabalhos de pesquisa realizados, para fundamentar uma recomendação específica para esta fase de desenvolvimento do cafeeiro, existindo praticamente apenas as recomendações gerais.

Ante esse quadro, objetivou-se com o trabalho avaliar os efeitos de dois regimes hídricos (irrigado e não-irrigado) e fertirrigação, combinados com doses de adubo para NPK, na fase de crescimento inicial, em duas variedades de café, na região noroeste do Paraná.

\section{Material e Métodos}

O experimento foi desenvolvido na área experimental do Centro Técnico de Irrigação (CTI), que pertence ao Departamento de Agronomia da Universidade Estadual de Maringá (UEM), em Maringá - PR, latitude $23^{\circ} 25^{\prime} \mathrm{S}$, longitude $51^{\circ} 57^{\prime}$ W e altitude média de $542 \mathrm{~m}$. Segundo Köppen, o clima é do tipo Cfa mesotérmico úmido com chuvas abundantes no verão e inverno seco. O solo onde foi instalado o experimento é da classe Nitossolo Vermelho distroférrico, com horizonte A moderado, textura argilosa, fase Floresta Tropical Subperenifólia (EMBRAPA, 1999).

Para a caracterização química e física do solo, foram coletadas amostras da área experimental, dividida em quatro setores, nas profundidades de 0 a $0,20 \mathrm{~m}$ e 0,20 a $0,40 \mathrm{~m}$ (Tabela 1 e Tabela 2), analisadas pelo Laboratório de Solos do Departamento de Agronomia da UEM.

O plantio foi realizado em dezembro de 2005 , com espaçamento de 2,0 m entre linhas de plantas e 1,0 m entre plantas na linha, o que configurou sistema adensado, com 5.000 plantas por hectare. A área total do experimento foi de 0,36 ha, sendo utilizadas 1.800 plantas de cafeeiro (Coffea arabica L.). Foram plantadas mudas das cultivares Obatã e IAPAR-59, de origem pé franco, distribuídas alternadamente a cada três linhas, num total de 24 linhas, com comprimento médio de $40 \mathrm{~m}$. 
Tabela 1. Características físicas do solo nas camadas de $0 \mathrm{~m}$ a $0,20 \mathrm{~m}$ e $0,20 \mathrm{~m}$ a $0,40 \mathrm{~m}$.

\begin{tabular}{cccccc}
\hline Camada & \multicolumn{5}{c}{$\mathrm{g} \mathrm{kg}^{-1}$} \\
\cline { 2 - 5 }$(\mathrm{m})$ & AREIA GROSSA & AREIA FINA & SILTE & ARGILA & TEXTURA \\
\hline $0-0,20$ & 40 & 160 & 100 & 700 & Muito Argilosa \\
$0,20-0,40$ & 40 & 120 & 50 & 790 & Muito Argilosa \\
\hline
\end{tabular}

Fonte: Elaboração dos autores.

Tabela 2. Características químicas do solo, antes do plantio do cafeeiro, nas camadas (C) de 0 a $0,20 \mathrm{~m}$ (A) e $0,20 \mathrm{~m}$ a $0,40 \mathrm{~m}(\mathrm{~B})$.

\begin{tabular}{|c|c|c|c|c|c|c|c|c|c|c|c|}
\hline \multirow[t]{2}{*}{ Setor } & \multirow{2}{*}{$\mathrm{C}$} & \multirow{2}{*}{$\begin{array}{c}\mathrm{pH} \\
\mathrm{CaCl}_{2}\end{array}$} & \multicolumn{6}{|c|}{$\mathrm{cmol}_{\mathrm{c}} \mathrm{dm}^{-3}$} & \multirow{2}{*}{$\begin{array}{c}\frac{\mathrm{mg} \mathrm{dm}}{-3} \\
\mathrm{P}\end{array}$} & \multirow{2}{*}{$\frac{\mathrm{g} \mathrm{dm}^{-3}}{\mathrm{C}}$} & \multirow{2}{*}{$\begin{array}{l}\% \% \\
\mathrm{~V}\end{array}$} \\
\hline & & & $\mathrm{H}^{1+}+\mathrm{Al}^{3+}$ & $\mathrm{Ca}^{2+}$ & $\mathrm{Mg}^{2+}$ & $\mathrm{K}^{1+}$ & SB & CTC & & & \\
\hline \multirow{2}{*}{1} & A & 5,0 & 4,61 & 5,01 & 2,23 & 0,66 & 7,90 & 15,51 & 1,9 & 14,22 & 63,2 \\
\hline & $\mathrm{B}$ & 5,0 & 4,96 & 6,24 & 2,65 & 0,36 & 9,25 & 14,21 & 0,3 & 11,85 & 65,1 \\
\hline \multirow{2}{*}{2} & A & 5,4 & 4,28 & 7,42 & 2,99 & 0,94 & 11,35 & 15,63 & 3,8 & 18,57 & 72,6 \\
\hline & B & 5,5 & 3,97 & 8,89 & 3,04 & 0,59 & 12,52 & 16,49 & 1,3 & 13,43 & 75,9 \\
\hline \multirow{2}{*}{3} & $\mathrm{~A}$ & 5,1 & 4,61 & 6,06 & 2,43 & 0,78 & 9,27 & 13,88 & 2,1 & 11,46 & 66,8 \\
\hline & B & 5,2 & 4,28 & 6,45 & 2,39 & 0,57 & 9,41 & 13,69 & 1,1 & 12,25 & 68,7 \\
\hline \multirow{2}{*}{4} & A & 5,3 & 4,28 & 6,44 & 2,50 & 0,60 & 9,54 & 13,82 & 0,6 & 9,88 & 69,0 \\
\hline & B & 5,4 & 3,97 & 6,16 & 2,30 & 0,26 & 8,72 & 12,69 & 0,1 & 9,10 & 68,7 \\
\hline
\end{tabular}

Fonte: Elaboração dos autores.

O delineamento experimental adotado foi o inteiramente casualizado, com parcelas subdivididas. As parcelas foram constituídas por quatro porcentagens da dose recomendada de adubação NPK, para formação inicial de cafeeiro, que é de $30 \mathrm{~g} \mathrm{~m}^{-1}$ para $\mathrm{N}$ e $\mathrm{K}$, e de $6 \mathrm{~g}$ $\mathrm{m}^{-1}$ para $\mathrm{P}$, conforme Matiello et al. (2005), as quais correspondem à porcentagem de $100 \%$. Além destas doses, foram testadas doses inferiores $\left(15 \mathrm{~g} \mathrm{~m}^{-1}\right.$ para $\mathrm{N}$ e $\mathrm{K} ; 3 \mathrm{~g} \mathrm{~m}^{-1}$ para $\mathrm{P}$ ) e doses superiores (45 $\mathrm{g} \mathrm{m}^{-1}$ e $60 \mathrm{~g} \mathrm{~m}^{-1}$ para $\mathrm{N}$ e K; $9 \mathrm{~g} \mathrm{~m}^{-1}$ e $12 \mathrm{~g} \mathrm{~m}^{-1}$ para $\mathrm{P})$, que equivalem aos porcentuais de $50 \%, 150 \%$ e $200 \%$ da dose recomendada para cada nutriente, respectivamente. Em ordem crescente, as doses de NPK foram chamadas de 1, 2, 3 e 4. As parcelas foram sorteadas, cada uma formando um setor da área experimental, com 0,09 ha. Em seguida, dentro de cada setor, as subparcelas foram compostas pelas linhas de plantas que receberam, por meio de sorteio, o tratamento regime hídrico não-irrigado e irrigado, e a fertirrigação.

Os tratamentos originaram-se da combinação das quatro doses de NPK (parcelas), com dois regimes hídricos (com irrigação, sem irrigação) e fertirrigação (subparcelas), totalizando 12 tratamentos, com dez repetições, com uma planta útil representando uma repetição. As avaliações dos tratamentos foram realizadas separadamente para cada cultivar de café (Obatã e IAPAR-59). Desta forma, cada unidade experimental constituiuse de uma planta útil, tomada ao acaso, nas linhas de cultivo, tendo como bordadura as linhas de plantas periféricas da área experimental e as três plantas iniciais e finais de cada linha. O início da diferenciação dos tratamentos ocorreu em agosto de 2006 (240 dias após o plantio).

Durante o período de condução do experimento, que foi de dezembro de 2005 a fevereiro de 2007 (457 dias após o plantio), procedeu-se aos tratos culturais e controle fitossanitário, sempre que necessário, seguindo as recomendações sugeridas por Matiello et al. (2005).

O sistema de irrigação localizada por gotejamento foi composto por emissores da marca Goldendrip, 
autocompensantes, com vazão nominal de $1,60 \mathrm{~L} \mathrm{~h}^{-1}$ e 1,80 L h ${ }^{-1}$, à pressão de 8,00 m.c.a e 12,00 m.c.a, respectivamente, e pressão de serviço variando de 6,00 m.c.a, no mínimo, a 23,00 m.c.a, no máximo. O espaçamento entre gotejadores na linha de plantio foi de 0,4 m, definido conforme metodologia proposta por Bernardo, Soares e Mantovani (2008). Entre linhas de plantio, os gotejadores foram espaçados em 2,0 m. Os gotejadores foram instalados sobre a superfície do solo, a $0,20 \mathrm{~m}$ do caule das plantas, de maneira que a superfície molhada formasse uma faixa contínua ao longo da linha de plantio.

O manejo da irrigação foi realizado através do software IRRIGA, também utilizado por Freitas, Ramos e Costa (2008). Para tanto, adotou-se os seguintes parâmetros indicados por Santinato, Fernandes e Fernandes (1996): coeficiente de cultura $(\mathrm{Kc})$ igual a 0,8 em todo período estudado; fator de disponibilidade hídrica de 0,5; temperatura ótima para a cultura de $25^{\circ} \mathrm{C}$ e área sombreada pela lavoura de café de $40 \%$. A evapotranspiração de referência $\left(\mathrm{ET}_{0}\right)$ foi estimada pelo método de Penman-Monteith. A metodologia do software baseia-se no monitoramento do ambiente físico com utilização de algumas variáveis climáticas para estimar a $\mathrm{ET}_{\mathrm{C}}$ (evapotranspiração da cultura) do cafeeiro em formação, a partir do produto entre $\mathrm{ET}_{0}$ e Kc (evapotranspiração de referência), que vai definir o seu consumo de água.

Determinados os parâmetros do solo, como capacidade de campo e ponto de murcha permanente (TRINTINALHA et al., 2004); e os da cultura, como o fator de disponibilidade hídrica para o cafeeiro, estima-se, então, a disponibilidade de água no solo. Com a determinação diária da ETc, o programa IRRIGA define a quantidade de água utilizada pela cultura, que possibilita a identificação do momento da irrigação e a lâmina de água necessária, considerando a precipitação efetiva ocorrida no período (Figura 1). Os dados climatológicos utilizados, tais como a temperatura média, máxima e mínima, e umidade relativa do ar, assim como a velocidade do vento, precipitação e insolação foram obtidos diariamente junto à Estação Climatológica da UEM, localizada a 2,1 km da área experimental. A precipitação mensal e as irrigações executadas, conforme indicação do software IRRIGA, durante o experimento, podem ser visualizadas na Figura 1.

Por ocasião do plantio e para todos os tratamentos, conforme Matiello et al. (2005), foram aplicados nas covas das mudas, manualmente e em dose única, 50 g planta ${ }^{-1}$ de $\mathrm{P}$, na forma de fosfato monoamônio (MAP), e 10 g planta $^{-1}$ de $\mathrm{N}$ e $\mathrm{K}$, na forma do formulado comercial 20-00-20. No momento em que se iniciou a diferenciação dos tratamentos, para os regimes hídricos irrigado e não-irrigado, utilizouse adubação NPK convencional com o formulado comercial 20-05-20. Esta foi parcelada em duas aplicações de cobertura, efetuadas nos meses de agosto e dezembro de 2006, isto é, com um intervalo de quatro meses, nas mesmas doses adotadas para a fertirrigação, porém mediante distribuição manual ao redor das plantas.

As aplicações das doses dos fertilizantes, nas parcelas fertirrigadas, foram parceladas em duas vezes e efetuadas nas mesmas épocas em que se adubou as parcelas irrigadas e não irrigadas. $\mathrm{O}$ procedimento de fertirrigação foi realizado através da injeção de solução, na linha principal do sistema de irrigação, antes do sistema de filtragem. Utilizouse como equipamento injetor uma bomba centrífuga de $0,5 \mathrm{cv}$, instalada de maneira afogada. Esta promovia a sucção da solução de água e fertilizante, a partir de um reservatório com capacidade de 150 L. O tempo de fertirrigação foi de 30 minutos. No manejo da fertirrigação, o sistema foi iniciado e finalizado somente com a aplicação de água por 15 minutos, como forma de estabilizar a vazão dos gotejadores e como medida preventiva de possíveis entupimentos. No período de adubação do experimento foram utilizados como fonte de NPK, na fertirrigação, nitrato de cálcio, fosfato monoamônio e nitrato de potássio. 
Figura 1. Ocorrência de precipitações pluviais e irrigações mensais executadas durante o período experimental.

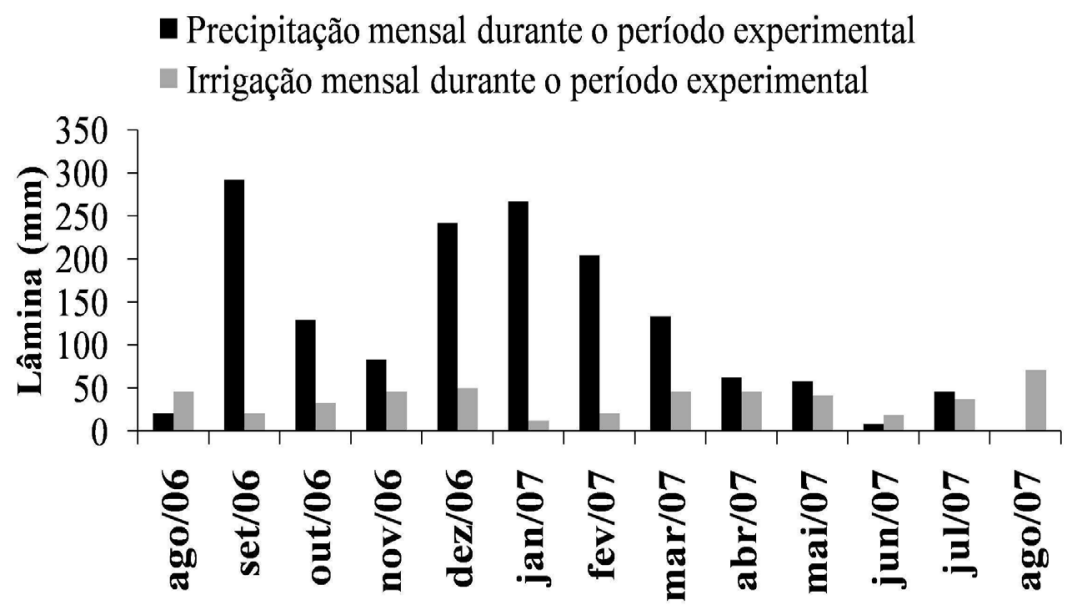

Fonte: Elaboração dos autores.

A única variação nos fertilizantes utilizados, com a diferenciação dos tratamentos, foi em relação à NPK, sendo os demais elementos aplicados da mesma maneira para todos os tratamentos.

Foram avaliadas as seguintes características de crescimento da cultura: diâmetro de caule, comprimento do primeiro ramo plagiotrópico e seu número de internódios. O diâmetro de caule foi medido com paquímetro digital a uma altura de $10 \mathrm{~cm}$ do solo. Para o comprimento dos primeiros ramos plagiotrópicos primários, previamente, estes foram selecionados e marcados em cada planta, e as medidas foram feitas utilizando-se trenas. Quanto ao número de internódios desses ramos, logo após a avaliação do comprimento, realizou-se contagem direta da quantidade de internódios que possuíam. Essas avaliações foram realizadas em fevereiro de 2007 (457 dias após plantio).

Os dados obtidos foram submetidos à análise de variância. Quando apresentaram diferenças significativas pelo teste $\mathrm{F}(\mathrm{P}<0,05)$, foi aplicado teste de Scott-Knott $(\mathrm{P}<0,05)$ para as varáveis qualitativas (regimes hídricos). As variáveis quantitativas (doses de NPK) foram estudadas mediante análise de regressão polinomial, cuja significância de modelos estatísticos foi detectada por meio do teste $\mathrm{F}(\mathrm{P}<0,05)$ da análise de variância e do teste $t$ de Student $(\mathrm{P}<0,05)$ para os coeficientes de regressão. Os procedimentos estatísticos foram realizados mediante uso do software estatístico Sisvar, conforme Ferreira (2000).

\section{Resultados e Discussão}

Os fatores regime hídrico e fertirrigação influenciaram significativamente a variável diâmetro de caule das plantas, em ambas cultivares de cafeeiro (Tabela 3). O aporte de água às plantas, por meio do regime hídrico irrigado e da fertirrigação, proporcionou os melhores resultados para essa variável, que foram superiores ao regime não-irrigado (Tabela 4). 
Tabela 3. Análise de variância para as características diâmetro de caule (DC), e comprimento (CRP) e número de internódios (NI) do primeiro ramo plagiotrópico primário para as cultivares de cafeeiro Obatã e IAPAR-59, UEM, Maringá-PR, 2007.

\begin{tabular}{|c|c|c|c|c|c|c|}
\hline \multirow{4}{*}{$\begin{array}{c}\text { Causas } \\
\text { de variação }\end{array}$} & \multicolumn{6}{|c|}{ Cultivares } \\
\hline & Obatã & IAPAR-59 & Obatã & IAPAR-59 & Obatã & IAPAR-59 \\
\hline & \multicolumn{2}{|c|}{$\mathrm{DC}$} & \multicolumn{2}{|c|}{ CRP } & \multicolumn{2}{|c|}{$\mathrm{NI}$} \\
\hline & \multicolumn{2}{|c|}{$\mathrm{mm}$} & \multicolumn{2}{|c|}{$\mathrm{cm}$} & \multicolumn{2}{|c|}{-} \\
\hline Dose de fertilizante & $0,0570^{\text {ns }}$ & $0,0053 *$ & $0,0080^{*}$ & $0,6724^{\mathrm{ns}}$ & $0,5251^{\text {ns }}$ & $0,0956^{\mathrm{ns}}$ \\
\hline $\begin{array}{l}\text { Regime hídrico e } \\
\text { fertirrigação }\end{array}$ & $0,0028^{*}$ & $0,0024 *$ & $0,0360^{*}$ & $0,0291^{*}$ & $0,0007 *$ & $0,0267^{*}$ \\
\hline Interação & $0,0696^{\text {ns }}$ & $0,2531^{\mathrm{ns}}$ & $0,1254^{\mathrm{ns}}$ & $0,08681^{\mathrm{ns}}$ & $0,0018^{*}$ & $0,2141^{\mathrm{ns}}$ \\
\hline Dose/Fertirrigação & $0,006 *$ & $0,0017 *$ & $0,021 *$ & $0,6961^{\mathrm{ns}}$ & $0,0141^{*}$ & $0,2493^{\text {ns }}$ \\
\hline Dose/Irrigação & $0,3764^{\text {ns }}$ & $0,4073^{\mathrm{ns}}$ & $0,4560^{\text {ns }}$ & $0,0840^{\mathrm{ns}}$ & $0,2080^{\text {ns }}$ & $0,0152 *$ \\
\hline Dose/Não-irrigado & $0,2252^{\text {ns }}$ & $0,8221^{\text {ns }}$ & $0,1695^{\mathrm{ns}}$ & $0,1759^{\text {ns }}$ & $0,0062 *$ & $0,9100^{\text {ns }}$ \\
\hline Média geral & 39,3 & 37,4 & 90,2 & 78,1 & 29,7 & 27,6 \\
\hline CV1(\%) & 9,09 & 6,5 & 7,81 & 9,17 & 6,50 & 9,18 \\
\hline CV2(\%) & 8,84 & 8,10 & 8,42 & 11,32 & 8,18 & 8,82 \\
\hline
\end{tabular}

* significativo em nível de $5 \%$ de probabilidade; ${ }^{\text {ns }}$ não-significativo em nível de $5 \%$ de probabilidade.

Fonte: Elaboração dos autores.

Tabela 4. Valores médios obtidos para diâmetro de caule (DC) e comprimento (CRP) e número de internódios (NI) do primeiro ramo plagiotrópico primário para as cultivares de cafeeiro Obatã e IAPAR-59 em diferentes regimes hídricos, UEM, Maringá-PR, 2007.

\begin{tabular}{|c|c|c|c|c|c|c|}
\hline \multirow{4}{*}{ Fatores } & \multicolumn{6}{|c|}{ Cultivares } \\
\hline & Obatã & IAPAR-59 & Obatã & IAPAR-59 & Obatã & IAPAR-59 \\
\hline & \multicolumn{2}{|c|}{ DC } & \multicolumn{2}{|c|}{ CRP } & \multicolumn{2}{|c|}{ NI } \\
\hline & \multicolumn{2}{|c|}{$\mathrm{mm}$} & \multicolumn{2}{|c|}{$\mathrm{cm}$} & \multicolumn{2}{|c|}{ - } \\
\hline Não-irrigado & $37,8 \mathrm{~b}$ & $36,0 \mathrm{~b}$ & $87,8 \mathrm{~b}$ & $75,9 \mathrm{~b}$ & $28,5 \mathrm{~b}$ & $26,8 \mathrm{~b}$ \\
\hline Irrigado & $39,5 \mathrm{a}$ & $38,1 \mathrm{a}$ & $92,3 \mathrm{a}$ & $80,3 \mathrm{a}$ & $30,2 \mathrm{a}$ & $27,5 \mathrm{~b}$ \\
\hline Fertirrigado & $40,6 \mathrm{a}$ & $38,2 \mathrm{a}$ & $90,3 \mathrm{a}$ & $78,2 \mathrm{a}$ & $30,5 \mathrm{a}$ & $28,3 \mathrm{a}$ \\
\hline
\end{tabular}

Médias seguidas de letras distintas, na coluna, diferem entre si pelo teste de Scott-Knott, em nível de 5\% de probabilidade.

Fonte: Elaboração dos autores.

O incremento do diâmetro de caule, em função dos regimes hídricos, assemelha-se aos dados de trabalhos de outros autores (SCALCO et al., 2002; SANTANA; OLIVEIRA; QUADROS, 2004), que detectaram diferenças significativas entre os valores médios de diâmetro de caule nos tratamentos com e sem irrigação, em que os irrigados apresentaram, em média, valores superiores àqueles sem irrigação.

Embora não tenha sido encontrada significância na interação entre os fatores principais dos tratamentos, para as duas cultivares, a análise do desdobramento, do fator dose de adubação dentro de cada regime hídrico e fertirrigação, revelou efeito das doses no diâmetro de caule das plantas dos tratamentos fertirrigados, para a cultivar IAPAR-59 (Tabela 3). Neste caso, a análise de regressão polinomial indicou um polinômio de segundo grau como sendo o modelo que melhor descreve o comportamento dessa variável, em função das doses de fertilizantes testadas (Figura 2). 
Figura 2. Diâmetro de caule do cafeeiro, cultivar IAPAR-59, no tratamento fertirrigado, em função das doses de fertilizantes.

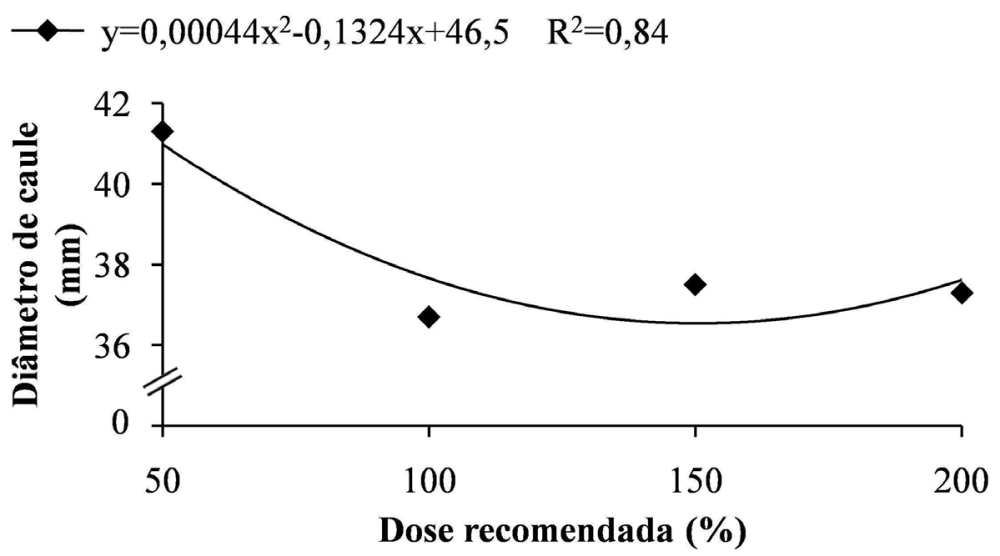

Fonte: Elaboração dos autores.

O diâmetro de caule da cultivar IAPAR-59 apresentou valor mínimo (36,54 mm) com 150,45\% da dose recomendada por Matiello et al. (2005), que equivale a $45,13 \mathrm{~g} \mathrm{~m}^{-1}$, para $\mathrm{N}$ e $\mathrm{K}$, e a 9,03 $\mathrm{g} \mathrm{m}^{-1}$, para P (Figura 2). Com base em Malavolta (2006), é possível afirmar que nestas doses tenha ocorrido maior acidificação da rizosfera, o que prejudicou o desenvolvimento das plantas. Esta constatação pode ser justificada considerando-se que a cultivar IAPAR-59 prefere solos mais férteis e que o solo da área experimental já apresentava alta fertilidade. Neste sentido, possivelmente, ocorreu maior atividade enzimática da $\mathrm{H}^{+}$-ATPase (prótonATPase), presente na membrana plasmática das células radiculares, com gasto de energia (ATP), para promover extrusão de prótons $\left(\mathrm{H}^{+}\right)$para a rizosfera e criar um gradiente eletroquímico, que permitisse a entrada uniporte ou antiporte de cátions e simporte de ânions. Além disso, a possível maior concentração de $\mathrm{K}^{+}$na solução do solo pode ter inibido, competitivamente, a absorção de outros cátions como $\mathrm{Ca}^{2+} \mathrm{e} \mathrm{Mg}^{2+}$, fundamentais para a manutenção da estrutura das paredes celulares de células vegetais. De maneira geral, o menor $\mathrm{pH}$ gerado na rizosfera altera a disponibilidade de nutrientes minerais para as plantas, uma vez que a maior disponibilidade de macronutrientes ocorre na faixa de $\mathrm{pH}$ entre 6 e 7 , sendo que nesta faixa não há grande limitação para os micronutrientes (MALAVOLTA, 2006).

De modo semelhante ao diâmetro de caule, o comprimento do primeiro ramo plagiotrópico primário foi influenciado pelos regimes hídricos e fertirrigação, em ambas cultivares (Tabela 3). Os maiores valores dessa variável ocorreram nos tratamentos que receberam irrigação e fertirrigação, e os menores, nas plantas não-irrigadas (Tabela 4). Os efeitos benéficos da prática da irrigação sobre o comprimento de ramos plagiotrópicos também foram constatados por Alves et al. (2000) e Karasawa (2001).

É importante destacar o efeito positivo que maiores comprimentos de ramos podem provocar na produtividade da cultura. Segundo Rena e Maestri (1986), em Coffea arabica, as inflorescências são formadas nas axilas das folhas opostas dos ramos plagiotrópicos primários (ramos laterais) crescidos na estação anterior, e esses internódios produzem flores apenas uma vez. Esse fato faz com que o crescimento dos ramos seja uma das características a serem usadas para se fazer previsões da futura safra. Portanto, quanto maior o crescimento dos ramos primários, maior será o potencial produtivo 
da planta no ano seguinte, pela presença de maior número de internódios e, consequentemente, maior número de inflorescências.

Para a cultivar Obatã, houve efeito significativo isolado das doses de adubação sobre o comprimento dos ramos plagiotrópicos (Tabela 3). Assim, pela análise de regressão polinomial, foi possível observar que um modelo linear melhor se adequou às médias observadas (Figura 3).

Figura 3. Comprimento do primeiro ramo plagiotrópico primário do cafeeiro, cultivar Obatã, em função das doses de fertilizantes.

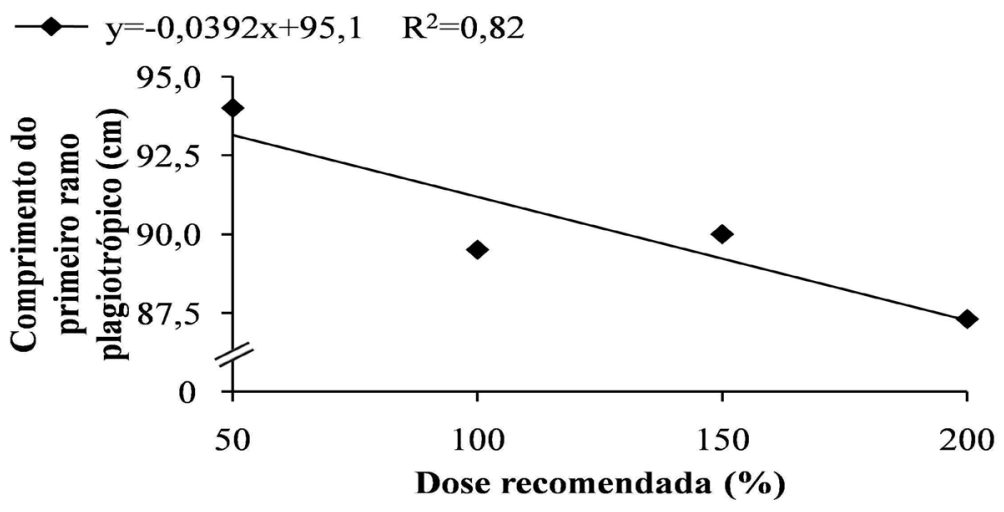

Fonte: Elaboração dos autores.

Observou-se decréscimo no comprimento dos primeiros ramos com o aumento da dose de NPK, sugerindo possível efeito deletério da elevação da concentração salina do solo, provocado pelas doses crescentes de fertilizantes. Esse resultado contraria os de Malavolta, Yamada e Aroaldo (1981), que trabalhando com cafeeiro adulto, cultivar Catuaí, observaram aumento do comprimento do primeiro ramo plagiotrópico em função de crescentes doses de adubação NPK.

Seguindo o mesmo comportamento das outras duas variáveis, é possível verificar que o número de internódios do primeiro ramo plagiotrópico primário foi influenciado, de maneira significativa, pelos regimes hídricos e fertirrigação (Tabela 3). Para a cultivar Obatã, novamente, as médias dos tratamentos irrigados e fertirrigados apresentaramse estatisticamente superiores às dos tratamentos não-irrigados. Os valores observados para a cultivar IAPAR-59, nas parcelas fertirrigadas, foram significativamente maiores que os das irrigadas e não-irrigadas, que por sua vez não apresentaram diferenças estatísticas entre si (Tabela 4). Alves et al. (2000) não constataram efeito significativo da prática da irrigação sobre o número de internódios do primeiro ramo plagiotrópico, de modo a concordar com os resultados observados para IAPAR-59, porém, contrariando os resultados verificados para Obatã.

O surgimento de maior número de internódios nos tratamentos fertirrigados sugere que para a próxima safra, as plantas fertirrigadas terão maior emissão de botões florais, e, possivelmente, maior produtividade, conforme relatam Rena e Maestri (1986). As diferentes respostas aos regimes hídricos e fertirrigação, por parte das cultivares de cafeeiro, podem ser um forte indicativo da influência das características genéticas de cada uma delas.

Para a cultivar Obatã, constatou-se interação significativa entre os fatores, e no desdobramento 
das doses de adubação dentro da fertirrigação e do regime hídrico não-irrigado observou-se diferenças significativas entre os tratamentos, no que diz respeito ao número de internódios do primeiro ramo plagiotrópico primário (Tabela 3). Através da análise de regressão polinomial, verificou-se que na fertirrigação houve resposta quadrática do número de internódios em função das doses de fertilizantes, enquanto que nos tratamentos não-irrigados a resposta foi linear (Figura 4).

Figura 4. Número de internódios do primeiro ramo plagiotrópico do cafeeiro de cultivar Obatã, nos tratamentos fertirrigado e não-irrigado, e de cultivar IAPAR-59, no regime hídrico irrigado, em função das doses de fertilizantes.

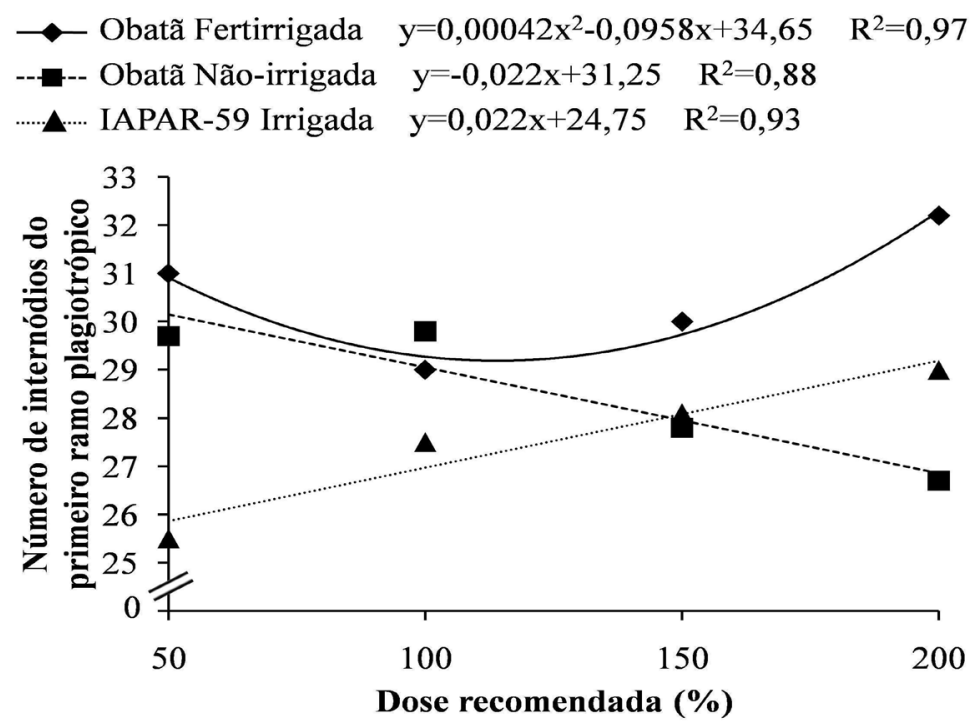

Fonte: Elaboração dos autores.

Com a fertirrigação, observou-se acréscimo no número de internódios da cultivar Obatã, a partir de $114,05 \%\left(34,35 \mathrm{~g} \mathrm{~m}^{-1}\right.$, para N e K, e $6,84 \mathrm{~g} \mathrm{~m}^{-1}$, para P) da dose recomendada por Matiello et al. (2005), em que se obteve o valor mínimo $(29,19)$ para a característica, até 200\% (Figura 4). Assim como a fertirrigação influencia positivamente o número de internódios do primeiro ramo plagiotrópico (Tabela 4), a aplicação da máxima dose de NPK via água de irrigação proporciona os maiores benefícios produtivos para Obatã (Figura 4), em virtude da possível maior emissão de botões florais. Isto ocorre, provavelmente, devido a uma melhor distribuição dos nutrientes ao longo do perfil do solo, que permite que a superfície de absorção do sistema radicular seja suficiente e favorável à aquisição de nutrientes, mesmo quando estes se encontram disponíveis em grandes quantidades na solução do solo. Desta forma, é possível um melhor aproveitamento nutricional pela planta, que contribui para o bom crescimento e desenvolvimento das suas estruturas vegetativas, e, posteriormente, das reprodutivas (MALAVOLTA, 2006; COELHO et al., 2009). É provável que este aproveitamento de nutrientes tenha ocorrido em menor escala, nas dosagens inferiores à $200 \%$, em função da menor quantidade de nutrientes aplicada.

Com o regime sem aplicação de água, a resposta linear decrescente observada, conforme o aumento das doses de adubação (Figura 4), pode estar associada a um possível efeito da concentração de sais (adubos), em área relativamente pequena $\mathrm{e}$ próxima à planta (projeção da copa), resultado do manejo convencional de aplicação (manual) das doses avaliadas. Contribui para esta possibilidade, o maior tempo de permanência das quantidades crescentes de adubo aplicadas próximas às plantas, 
considerando que este regime hídrico não recebeu irrigação, o que aumenta o tempo de solubilização e diminui a movimentação, em profundidade, dos nutrientes no perfil do solo.

Ainda que a interação entre fatores não tenha sido significativa, para a cultivar IAPAR-59, verificou-se, no desdobramento das doses dentro do regime irrigado, efeitos significativos (Tabela 3). A análise de regressão indicou que o modelo, que melhor explicou o número de internódios em função das doses, foi do tipo linear (Figura 4). O aumento crescente no número de internódios da dose 1 até a 4 , sugere que houve efeito positivo da adubação NPK no surgimento de novos internódios no cafeeiro, possibilitando, assim, elevar sua futura produção de frutos, uma vez que estas duas características estão diretamente relacionadas (IBC, 1986). Estes resultados estão de acordo com Tesha e Kumar (1979), que observaram aumento significativo do número de internódios, em plantas de cafeeiro, pela aplicação de $\mathrm{N}$ e $\mathrm{K}$ associada a teores adequados de umidade no solo.

Para diâmetro de caule, e comprimento e número de internódios do primeiro ramo plagiotrópico, nas cultivares Obatã e IAPAR-59, os tratamentos irrigados e fertirrigados proporcionaram os maiores resultados, exceto para o número de internódios, na cultivar IAPAR-59, no qual os fertirrigados foram superiores aos irrigados e não-irrigados. Desta forma, a fertirrigação é uma alternativa a ser utilizada, mostrando que a aplicação conjunta de água e fertilizantes traz benefícios para o crescimento de plantas de cafeeiro na fase de formação.

O número de internódios do primeiro ramo plagiotrópico aumentou com a irrigação e diminuiu no sequeiro, linearmente, para IAPAR-59 e Obatã, respectivamente, conforme o aumento das doses de NPK. Para IAPAR-59, este resultado indica a grande importância da irrigação para a melhora do aproveitamento nutricional pelo sistema radicular, que pode resultar em maior emissão de botões florais, mesmo quando a adubação é efetuada de maneira convencional, o que não ocorreu para
Obatã, em virtude do regime de sequeiro. $\mathrm{Na}$ fertirrigação, houve redução do diâmetro de caule em doses superiores à menor dose testada, para IAPAR-59. Ainda que esta redução não tenha sido observada para Obatã, o máximo número de internódios foi obtido com a máxima dose aplicada mediante uso da fertirrigação. Neste caso, o efeito benéfico sobre o número de internódios é indicativo de maior produtividade.

\section{Conclusões}

A fertirrigação e a irrigação favoreceram o crescimento inicial de ambas cultivares de cafeeiro. Para a cultivar IAPAR-59, o número de internódios é favorecido pela fertirrigação. $O$ número de internódios aumenta com a irrigação e diminui no sequeiro, de modo linear, para IAPAR-59 e Obatã, respectivamente, em função do aumento das doses de NPK. Na fertirrigação há redução do diâmetro de caule em doses superiores à menor dose testada, para IAPAR-59, enquanto que o maior número de internódios é obtido com a máxima dose utilizada, para Obatã.

\section{Agradecimentos}

Os autores agradecem ao CNPq e à Fundação Araucária, pelo apoio financeiro e oportunidade de desenvolvimento do projeto de pesquisa de Doutorado, por meio do qual foi possível elaborar o presente artigo científico.

\section{Referências}

ALVES, M. E. B.; FARIA, M. A.; GUIMARÃES, R. J.; MUNIZ, J. A.; SILVA, E. L. Crescimento do cafeeiro sob diferentes lâminas de irrigação e fertirrigação. Revista Brasileira de Engenharia Agrícola e Ambiental, Campina Grande, v. 4, n. 2, p. 219-225, 2000.

ARANTES, K. R.; FARIA, M. A.; REZENDE, F. C. Recuperação do cafeeiro (Coffea arabica L.) após recepa, submetido a diferentes lâminas de água e parcelamento da adubação. Acta Scientiarum - Agronomy, Maringá, v. 31, n. 2, p. 313-319, 2009. 
BERNARDO, S.; SOARES, A. A.; MANTOVANI, E. C. Manual de irrigação. 8. ed. Viçosa: UFV, 2008. 625 p.

CARVALHO, G. R.; GUERREIRO FILHO, O.; PEREIRA, A. A.; ALMEIDA, S. R.; MATIELO, J. B.; BARTOLO, G. F.; SERA, T.; MOURA, W. M.; MENDES, A. N. G.; REZENDE, J. C.; FONSECA, A. F. A.; FERRÃO, M. A. G.; FERRÃO, R. G.; NACIF, A. P.; SILVAROLLA, M. B. Cultivares de café arábica. In: CARVALHO, C. H. S. (Ed.). Cultivares de café: origem, características e recomendações. Brasília: Embrapa Café, 2008. v. 1, p. 192-194.

COELHO, G.; SILVA, A. M.; REZENDE, F. C.; SILVA, R. A.; CUSTÓDIO, A. A. P. Efeitos de épocas de irrigação e de parcelamento de adubação sobre a produtividade do cafeeiro 'Catuaí'. Ciência e Agrotecnologia, Lavras, v. 33, n. 1, p. 67-73, 2009.

DAMATTA, F. M.; RONCHI, C. P.; MAESTRI, M.; BARROS, R. S. Ecophysiology of coffee growth and production. Brazilian Journal of Plant Physiology, Campinas, v. 19, n. 4, p. 485-510, 2007.

EMPRESA BRASILEIRA DE PESQUISA AGROPECUÁRIA - EMBRAPA. Centro Nacional de Pesquisa de Solos. Sistema brasileiro de classificação de solos. Rio de Janeiro: EMBRAPA/CNPSO, 1999. 412 p.

FERREIRA, D. F. Manual do sistema Sisvar para análises estatísticas. Lavras: UFLA, 2000. 63 p. Disponível em: $<$ http://www.dex.ufla.br/ danielff/sisvarmanual.pdf $>$. Acesso em: 16 jun. 2006.

FREITAS, W. S.; RAMOS, M. M.; COSTA, S. L. Demanda de irrigação da cultura da banana na bacia do Rio São Francisco. Revista Brasileira de Engenharia Agrícola e Ambiental, Campina Grande, v. 12, n. 4, p. 343-349, 2008.

INSTITUTO BRASILEIRO DO CAFÉ - IBC. Cultura do café no Brasil: pequeno manual de recomendações. Rio de Janeiro: IBC, 1986. 214 p.

JORDÃO, C.; OLIVEIRAJÚNIOR, O. R.; MENDONÇA, P. L. Irrigação do cafeeiro: recomendações gerais. Monte Carmelo: COOXUPÉ, 1996. 32 p.

KARASAWA, S. Crescimento e produtividade do cafeeiro (Coffea arabica L. cv. Topázio MG-1190) sob diferentes manejos de irrigação localizada. 2001. Dissertação (Mestrado em Engenharia Agrícola) Universidade Federal de Lavras, Lavras.

MALAVOLTA, E. Manual de nutrição mineral de plantas. Piracicaba: Editora Ceres, 2006. 631 p.

MALAVOLTA, E.; YAMADA, T. G.; AROALDO, J. Nutrição e adubação do cafeeiro. Piracicaba: Instituto da Potassa e Fosfato, 1981. 226 p.

MARTINS, C. C.; REIS, E. F.; BUSATO, C.;
PEZZOPANE, J. E. M. Crescimento inicial do café Conilon (Coffea canephora Pierre ex Froehner) sob diferentes lâminas de irrigação. Engenharia na Agricultura, Viçosa, v. 14, n. 3, p. 193-201, 2006.

MATIELLO, J. B.; SANTINATO, R.; GARCIA, A. W. R.; ALMEIDA, S. R.; FERNANDES, D. R. Cultura de café no Brasil: novo manual de recomendações. Rio de Janeiro: MAPA; PROCAFE, 2005. 438 p.

PEZZOPANE, J. R. M.; CASTRO, F. S.; PEZZOPANE, J. E. M.; BONOMO, R.; SARAIVA, G. S. Zoneamento de risco climático para o café Conilon no Estado do Espírito Santo. Ciência Agronômica, Fortaleza, v. 41, n. 3, p. 341-348, 2010.

PRADO, R. M.; NASCIMENTO, V. M. Manejo e adubação do cafeeiro. Ilha Solteira: UNESP, FEIS, 2003. 274 p.

RENA, A. B.; MAESTRI, M. Fisiologia do cafeeiro. In: RENA, A. B.; MALAVOLTA, E.; YAMADA, T. (Ed.). Cultura do cafeeiro: fatores que afetam a produtividade. Piracicaba: Potafós, 1986. p. 13-85.

SANTANA, M. S.; OLIVEIRA, C. A. S.; QUADROS, M. Crescimento inicial de duas cultivares de cafeeiro adensado influenciado por níveis de irrigação localizada. Engenharia Agrícola, Jaboticabal, v. 24, n. 3, p. 644-653, 2004.

SANTINATO, R.; FERNANDES, A. L. T.; FERNANDES, D. R. Irrigação na cultura do café. Campinas: Arbore, 1996. 146 p.

SCALCO, M. S.; MORAIS, A. R.; COLOMBO, A.; CARVALHO, C. H. M.; FARIA, M. A.; MELO, L. Q.; SILVA, E. L. Influência de diferentes critérios de irrigação e densidades de plantio sobre o crescimento inicial do cafeeiro. In: SIMPÓSIO BRASILEIRO DE PESQUISA EM CAFEICULTURA IRRIGADA, 5., 2002, Araguari, Anais... Uberlândia: Universidade Federal de Uberlândia, 2002. p. 150-55.

SILVA, A. M.; RESCK, D. V. S.; FRANÇA-DANTAS, M. S.; FEITOZA, L.; EVANGELISTA, B. A. Influência do início da irrigação e do parcelamento de adubação na produtividade do cafeeiro no sul de Minas - safra 2001/2002. In: SIMPÓSIO DE PESQUISA DOS CAFÉS DO BRASIL, 3., 2003, Porto Seguro. Anais... Brasília: Embrapa Café, 2003. p. 140.

TESHA, A. J.; KUMAR, D. Effects of soil moisture, potassium and nitrogen on mineral absorption and growth of Coffea Arabica L. Turrialba, San José, v. 29, n. 3, p. 213-218, 1979.

TRINTINALHA, M. A.; GONÇALVES, A. C. G.; TORMENA, C. A.; COSTA, A. C. S.; FOLEGATTI, M. V.; FREITAS, P. S. L.; REZENDE, R. Comparação dos sistemas TDR e ECHO para medida de umidade, em um solo argiloso e em areia. Acta Scientiarum, Maringá, v. 26, n. 3, p. 353-360, 2004. 